\title{
Energy Flexibility Assessment of a Zone with Radiant Floor Heating System by Means of Experimental Measurements
}

\author{
Ali Saberi Derakhtenjani ${ }^{1, *}$ and Andreas Athienitis ${ }^{1}$ \\ ${ }^{1}$ Center for zero energy building studies (CZEBS), Concordia University, Montreal, Quebec, Canada
}

\begin{abstract}
This article investigates the potential energy flexibility of a thermal zone that contains a hydronic radiant floor heating system embedded in a concrete slab. The energy flexibility of the zone is quantified from experimental measurements for a specific zone air set point change. The experiment was carried out in an experimental perimeter zone test cell (PZTC) designed to simulate the conditions of an office space near a window which has a radiant floor heating system. The PZTC is located inside a controlled environmental chamber (EC). The EC provides the desired exterior conditions. The temperature inside the PZTC is controlled with a thermostat that adjusts the heating power delivered from the hydronic pipes to the slab. It was observed that modulating the zone air temperature setpoint results in significant changes in the heating load, and thus providing a certain amount of energy flexibility. Application of the quantified energy flexibility along with applicable strategies in response to a specific price signal profile are discussed.
\end{abstract}

\section{Introduction}

The penetration of renewable energy sources (RES) is increasing worldwide, with a $26 \%$ increase of installed photovoltaics (PV) capacity to $177 \mathrm{GW}$ and $16 \%$ increase of wind capacity to $370 \mathrm{GW}$ from 2013 to 2014, respectively $[1,2]$. The trend is expected to continue and many countries are dedicated in increasing the RE share in energy system and already have ambitious targets. The Renewable Energy Directive requires the EU to fulfil at least $20 \%$ of its total energy needs with renewables by 2020. However, integrating the intermittent and stochastic production capacity with a notable RES share into existing power systems is a major challenge. At the same time, RES are not only in centralized plants, but also are evolving in a distributed manner, as well as distributed storage systems (such as thermal storage systems, battery storage, etc.). The flexibility to manage any mismatch between consumption and generation can come from either the supply side (through the use of conventional power plants or storage) or from the demand side [3]. The concept of energy flexible building (EFB) is introduced by IEA EBC Annex 67[4]. The current definition of building energy flexibility based on annex67 is "the ability to manage building demand and generation according to local climate conditions, user needs, and energy network requirements"[4].

Due to the strong dependence to the boundary conditions and uncertainty on evaluation, energy flexibility quantification in buildings is one of the topics of greatest interest in current scientific research[5]. Buildings can provide different flexibility services to reduce peak loads and shift demand in accordance with local RES production, e.g. utilization of thermal mass [69], storage in batteries, charging of electric vehicles and adjustability of the HVAC system use [4]. The use of structural thermal storage (STES) is often suggested as a low-cost key technology to mitigate potential production and distribution capacity issues and to improve the penetration of renewable energy sources. Therefore, a quantitative assessment of the energy flexibility provided by structural thermal energy storage is essential to large scale deployment of thermal mass as the active storage technologies in an active demand response (ADR) context. The available storage capacity expresses the amount of energy that can be added to the STES during a specific ADR event. Thus, the heat that can be stored within a dwelling not only depends upon the thermal properties of the building fabric, but also on the properties and actual use of the heating and ventilation systems [10]. Four performance indicators or characteristics for ADR are defined and quantification methods for the ADR potential of structural thermal storage are presented by [5, 11] including: available structural energy storage capacity $\left(C_{\mathrm{ADR}}\right)$, the storage efficiency $\left(\eta_{\mathrm{ADR}}\right)$, the power shifting capacity $\left(Q_{\delta}\right)$ and the state of charge (SOC). The indicators are briefly presented here.

The conceptual representation of storage capacity quantification is presented in reference [5] and shown in Fig. 1. As explained in [5], the ADR event is simulated starting from a building with an indoor temperature equal to the minimum comfort temperature. During the ADR event the temperature set point for the heating system is increased by $\mathrm{dT}_{\text {comf }}\left({ }^{\circ} \mathrm{C}\right)$ for the time duration of $l_{\mathrm{ADR}}$. $C_{\mathrm{ADR}}$ is calculated by the integral of the difference between the heating power during the active demand

\footnotetext{
* Corresponding author: ali.saberi.mech $@$,gmail.org
} 
response $(\mathrm{ADR})$ event $\left(Q_{\mathrm{ADR}}|\mathrm{W}|\right)$ and the heating power in normal reference operation $\left(Q_{\mathrm{Ref}}|\mathrm{W}|\right)$ represented by the dark gray area in Fig. 1 [5].

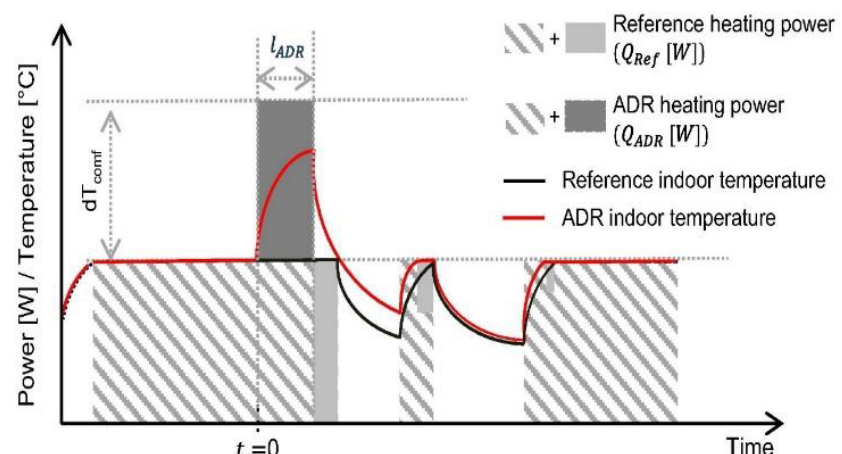

Fig. 1. Conceptual representation of the measures used to quantify the available storage capacity[5]

$$
C_{A D R}=\int_{0}^{l_{A D R}}\left(Q_{A D R}-Q_{R e f}\right) d t
$$

$C_{\mathrm{ADR}}$ is calculated for the case study for both upward and downward flexibility events.

The storage efficiency $\left(\eta_{\mathrm{ADR}}\right)$ represents the fraction of the heat that is stored during the ADR event that can be used subsequently to reduce the heating power needed to maintain thermal comfort.

$$
\eta_{A D R}=1-\frac{\int_{0}^{\infty}\left(Q_{A D R}-Q_{\operatorname{Re} f}\right) d t}{\int_{0}^{l_{A D R}}\left(Q_{A D R}-Q_{\operatorname{Re} f}\right) d t}
$$

The power shifting capacity is the relation between the change in heating power $\left(Q_{\delta}\right)$ and the duration $\left(t_{\delta}\right)$ that this shift can maintained before the normal operation of the system, i.e. thermal comfort, is jeopardized:

$$
Q_{\delta}=Q_{A D R}-Q_{\operatorname{Re} f}
$$

The more energy has been stored within the building thermal mass, the longer duration to reduce the heating power can be obtained. The state of charge (SOC) is used to explain the fraction of stored energy at time t compared to the total storage capacity:

$$
S O C=\frac{E_{t h}(t)-E_{t h, \text { in }}(t)}{E_{t h, \text { max }}(t)-E_{t h, \text { min }}(t)}
$$

The objective of this article is to investigate and quantify the energy flexibility that can be offered by the thermal mass of a radiant floor heating system through experimental measurements. The following section describes the test facility and the PZTC characteristics.

\section{BUILDING and system description}

The case study is conducted in the perimeter zone test cell (PZTC) located at Concordia University's solar simulator/environmental chamber (SSEC) laboratory. The temperature of the environmental chamber (EC) can be controlled within a wide range (between $-40{ }^{\circ} \mathrm{C}$ and $+50{ }^{\circ} \mathrm{C}$ ) and thus allows for a great deal of flexibility in terms of testing conditions. Fig. 2 shows the schematic of the SSEC, perimeter zone, radiant floor system and the mechanical room.

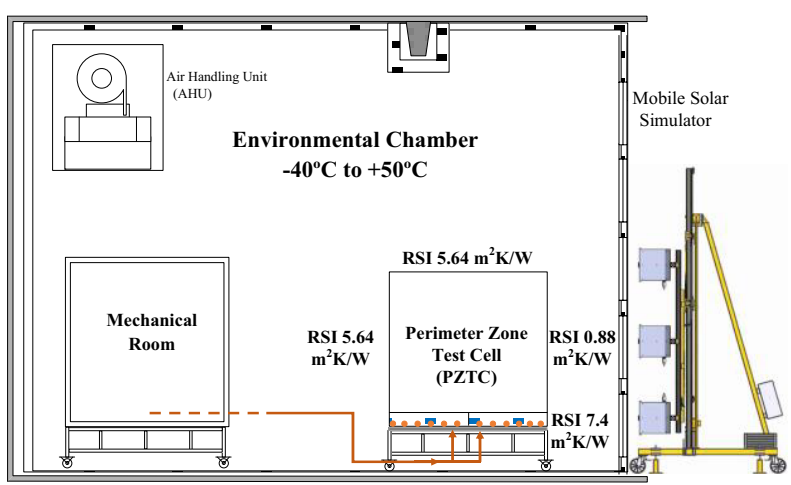

Fig. 2. Schematic of SSEC with PZTC and radiant floor

The PZTC is a $3 \mathrm{~m} \times 3 \mathrm{~m} \times 3 \mathrm{~m}$ room placed inside the environmental chamber and it has a radiant floor heating system. The side and back walls and ceiling consist of 4 in $(10 \mathrm{~cm})$ insulation having the R-value of R32 (RSI 5,64 ). The front wall is a BIPV/T façade with R5 (RSI $0,88)$ thermal resistance. The floor is made of an $8 \mathrm{~cm}$ thick concrete with insulation at the bottom. The pipes of the radiant floor system are made of conventional crosslinked polyethylene (PEX), and a have an external diameter of $1.75 \mathrm{~cm}$. The pipes are installed in a "foam matrix" of insulating material that also facilitates keeping them in place. The pipes have an approximate separation of $15 \mathrm{~cm}$ between them. A mechanical room provides controlled flow rate of fluid (propylene-glycol and water mixture) for the radiant floor. The floor is divided into two slabs as shown in Fig. 3. The schematic in Fig. 4 shows the total concrete slab thickness as well as the pipe diameter.
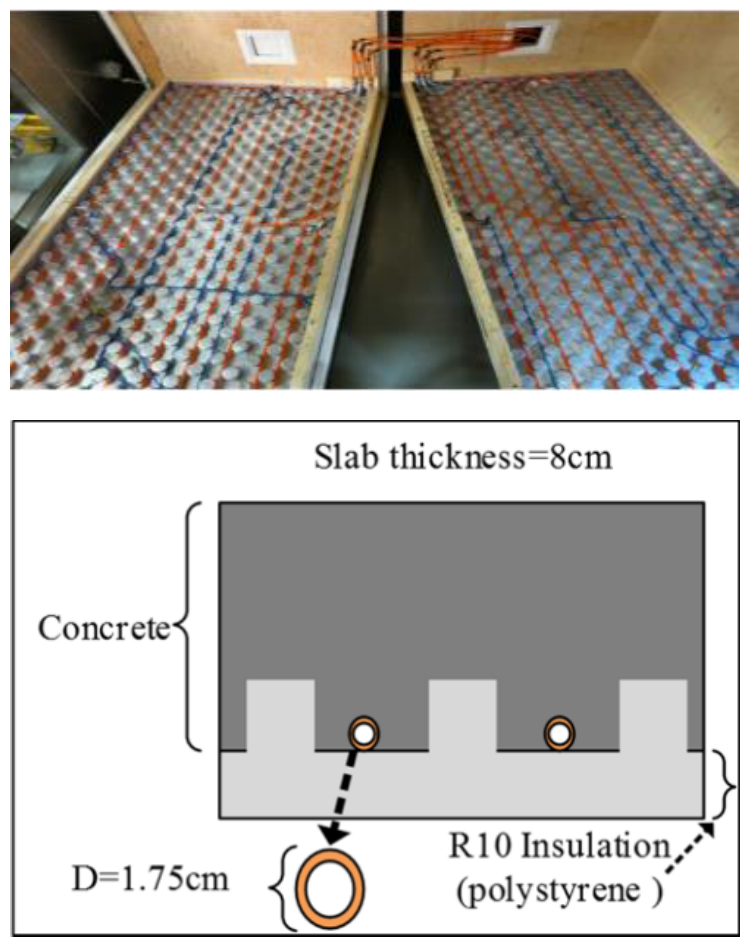

Fig. 3. Radiant floor pipes (before pouring the concrete) and the schematic 


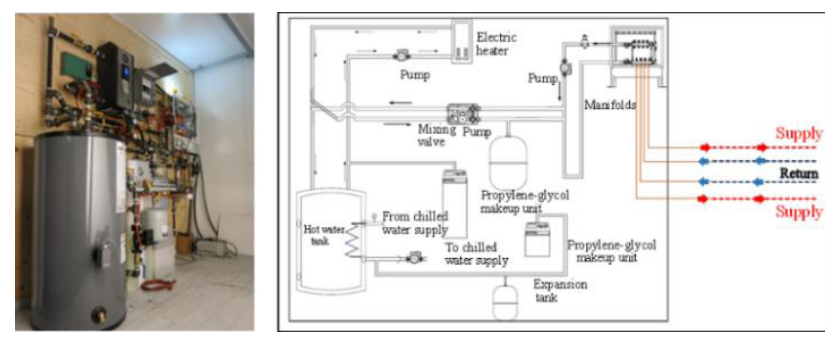

Fig. 4. Mechanical room and its schematic

A number of studies were carried out on the thermal characterization of the facility's radiant floor system itself when exposed to exterior conditions ([12],[13]). These studies were done before installing the front wall of the PZTC and only the radiant floor was studied and not the whole PZTC. The study that is presented in this document is the first experimental study on the PZTC and its energy flexibility.

\section{Methodology: control strategy and implementation}

This experiment was carried out by changing the zone air setpoint using the zone thermostat. The thermostat controls the room air and floor temperature for a hydronic heating zone using Pulse Width Modulation (PWM) technology to modulate the flowrate length. A slab sensor is included with the thermostat to measure floor temperature to protect the floor from overheating and enhance comfort. In the experiment, the maximum allowable floor temperature is set to be $29{ }^{\circ} \mathrm{C}$ based on the ASHRAE standard 55.

The control of the system is based on an assumed price signal. Therefore, it is investigated how much flexibility can be obtained by modulating the air temperature setpoint from the baseline room air temperature of $22^{\circ} \mathrm{C}$ (reference case) to the comfort limits of the zone $\left(20^{\circ} \mathrm{C}\right.$ and $\left.24^{\circ} \mathrm{C}\right)$. The increasing/decreasing of the setpoint is done manually by entering the room and increasing the temperature on the thermostat, waiting for the desired period (about 6 hours) after which the temperature is returned to the baseline $\left(22^{\circ} \mathrm{C}\right)$ again manually (Fig. 5). Both setpoint increase and decrease from the baseline are considered to examine the upward and downward flexibility of the system. The ambient (environmental chamber) temperature was set to $5^{\circ} \mathrm{C}$ constant.

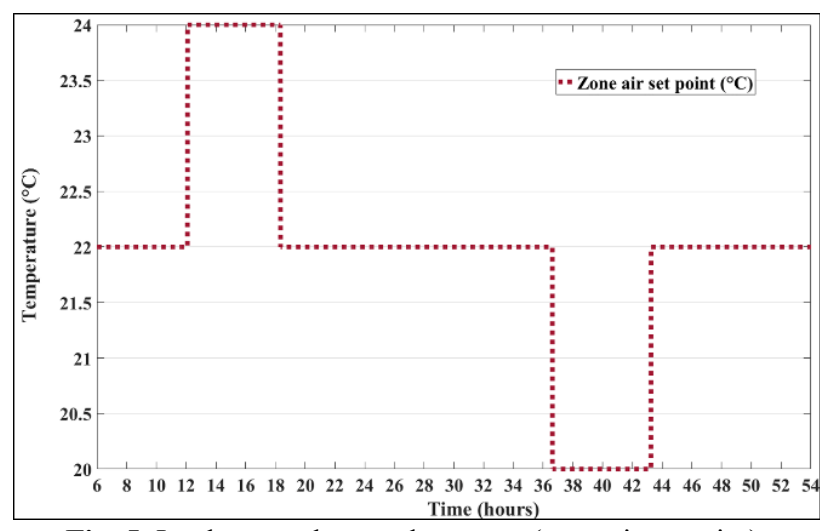

Fig. 5. Implemented control strategy (zone air setpoint)

\section{Results}

Fig. 6 shows the system flowrate (actual measurements and the moving mean value) before and during the active demand response (ADR) event (12-18 hours and 37-43 hours), when the zone air temperature is modulated accordingly. As it can be observed from Fig. 6, before hour of 12 there is a steadier on/off to the system flowrate through pulse-width modulation in order to keep the zone temperature at $22^{\circ} \mathrm{C}$. Then, between hours of 12 and 18 when the temperature is set to be increased to $24{ }^{\circ} \mathrm{C}$ the controller keeps the flowrate near maximum (1 gpm) and keeps the flow running for a much longer period until the surface temperature gets really hot around the hour of 14.5 (see Fig. 9) so then the flow is stopped for about 1.5 hours. The flow is started again for another 1.5 hours (16-17.5 hours) and stopped at hour 18 when the setpoint is reduced to $22^{\circ} \mathrm{C}$ from $24^{\circ} \mathrm{C}$. After hour 18 it is observed that there is no heating power to the system for more than 4 hours. Therefore, it can be stated that this strategy gives a 4hours power shifting capacity compared to the baseline heating power profile (constant $22^{\circ} \mathrm{C}$ zone temperature).
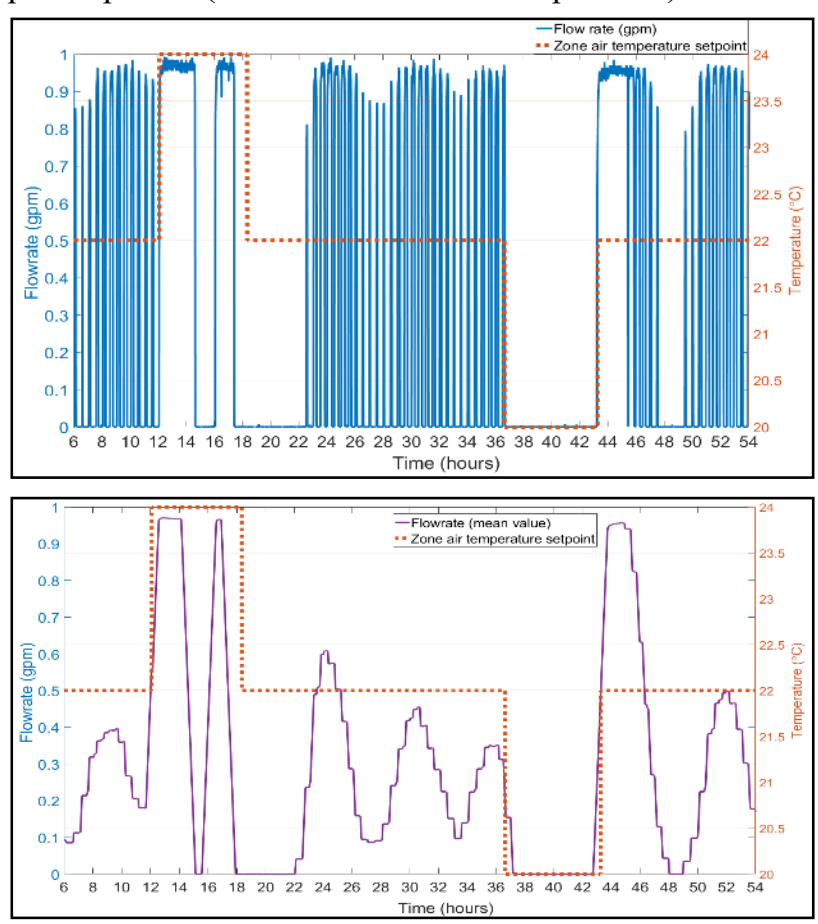

Fig. 6. Radiant floor System flowrate actual measurement (top), moving-window mean value vs room setpoint modulations (bottom)

Heating power to the radiant floor is calculated by using the flowrate (mdot), supply and return temperatures difference $(\Delta \mathrm{T})$ as:

$$
Q=\operatorname{mdot} \times C_{p} \times \Delta T
$$

For the ADR events, hours 12 to 18 and 37 to 43 , the energy flexibility of the system is calculated using equation (1). As shown in Fig. 7, the upward flexibility is equal to $195 \mathrm{Wh} / \mathrm{m}^{2}$ and the downward flexibility is 237 $\mathrm{Wh} / \mathrm{m}^{2}$. Also, an increase of $125 \mathrm{~W}$ in the heating power in the rebound effect of the downward flexibility (hour 43) compared to the one for the upward flexibility (hour 12) can be observed. This increase in heating power is due 
to the fact that at hour 43 no heat has been injected into the system for 6 hours. Therefore, a higher spike in the heating power compared to hour 12 is observed.

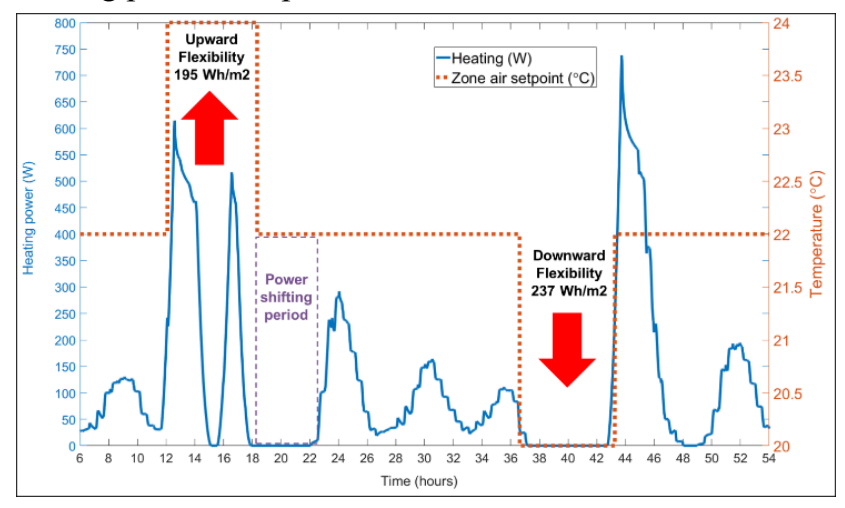

Fig. 7. Heating power of the radiant floor system and the upward/downward flexibility calculation

This setpoint modulation strategy described above can be defined and applied to a price signal shown in Fig. 8. Therefore, when there is a high price signal for a certain period of time in the forecast, the zone setpoint can be increased by $2^{\circ} \mathrm{C}$ for a certain period and then get back to the normal operating condition. It is observed that with this strategy our system offers about 4 hours of power shifting capacity. Also with the downward flexibility it will be possible to decrease the rebound effect by using a ramp profile or other transition paths for which we need to install a programmable thermostat.

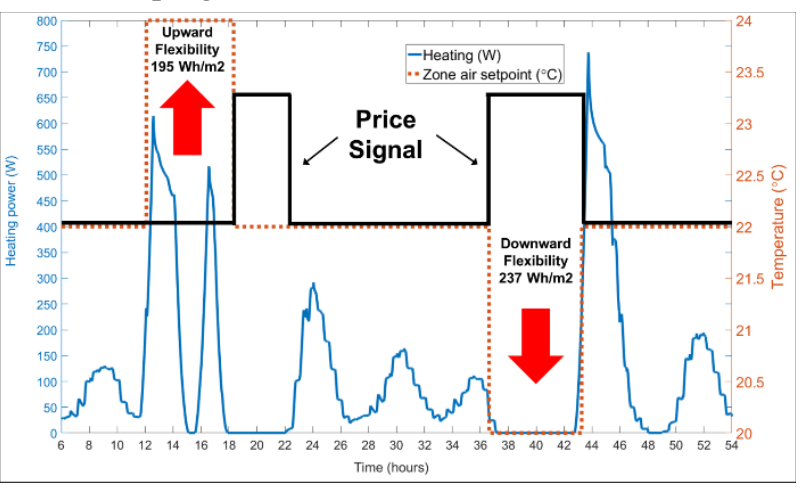

Fig. 8. Price signal

Fig. 9 shows the radiant floor surface temperature as well as the zone operative temperature and the exterior temperature conditioned by the environmental chamber. It is observed that the operative temperature is within the comfort limits almost all the time. Also, it can be observed that when the floor temperature reaches the $29^{\circ} \mathrm{C}$ limit (around hours of 15), the controller shuts down the heat input by turning off the flowrate for the radiant floor. In this experiment large amount of heat loss through the $\mathrm{BIPV/T}$ façade was observed mostly due to thermal bridges from the aluminium framing of the façade. It is required to add more insulation to the façade for the future tests especially when it is desired to do tests with an exterior temperature which is below $0^{\circ} \mathrm{C}$.

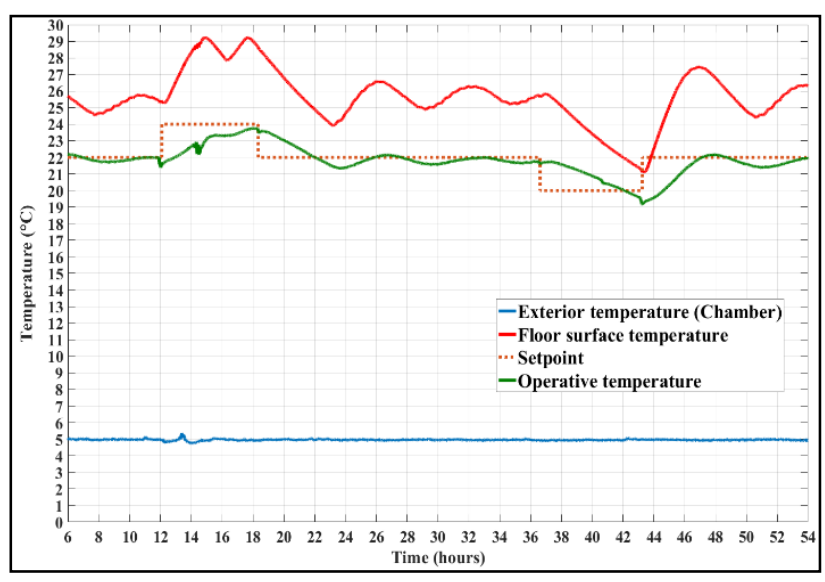

Fig. 9. Floor surface and operative temperatures

\section{Conclusion}

This paper presented an experimental evaluation and quantification of the energy flexibility for a zone with radiant floor heating system. It is observed that due to the significant thermal mass of the floor, about $0.2 \mathrm{kWh} / \mathrm{m}^{2}$ of energy flexibility and 4 hours of power shifting can be achieved. The quantified energy flexibility is especially useful for the predictive and reactive response to the grid's penalty signal in order to reduce the energy consumption and peak power significantly during the peak demand periods. Further work is being carried out to develop a generalized methodology that includes thermal models of the system. The methodology can be applied to any similar system in order to optimize the utilization of the energy flexibility offered by such systems.

\section{Acknowledgment}

Technical and financial support of this research through NSERC/Hydro-Quebec industrial research chair at Concordia University is greatly acknowledged.

\section{References}

1. IEAPVPS, 'Snapshot of global PV markets 2014'. (2014).

2. GWEC, 'Global wind statistics 2014'. (2014).

3. Lund, P., Lindgren, J., Mikkola, J. and Salpakari, J., 'Review of energy system flexibility measures to enable high levels of variable renewable electricity'. Renewable and Sustainable Energy Reviews (2015). 45: p. 785-807.

4. Jensen, S., Marszal, A.J., Lollini, R., Paust, W., Armin, K., Engelmann, P., Stafford, A. and Reynders, G., 'IEA EBC Annex 67 Energy Flexible Buildings'. Energy and Buildings, (2017).

5. Reynders, G., Lopes, R.A., MarszalPomianowska, A., Aelenei, D., Martins, J. and Saelens, D., 'Energy flexible buildings: An 
evaluation of definitions and quantification methodologies applied to thermal storage'. Energy and Buildings, (2018). 166: p. 372-390.

6. Reynders, G., Diriken, J. and Saelens, D.(2016) 'Quantifying the active demand response potential: impact of dynamic boundary conditions.'. CLIMA 2016 - proceedings of the 12th REHVA World Congress. 2016.

7. Le Dreau, J. and Heiselberg, P., 'Energy flexibility of residential buildings using short term heat storage in the thermal mass'. Energy, (2016). 111: p. 991-1002.

8. Foteinaki, K., Rongling, L., Heller, A. and Rode, C., 'Heating system energy flexibility of lowenergy residential buildings'. Energy and Buildings, (2018). 180: p. 95-108.

9. Weiß, T., Fulterer, A.M. and Knotzer, A., 'Energy flexibility of domestic thermal loads - a building typology approach of the residential building stock in Austria'. Advances in Building Energy Research, (2019). 13(1): p. 122-137.

10. Reynders, G., Diriken, J. and Saelens, D.(2015) 'A generic quantification method for the active demand response potential of structural storage in buildings'. 14th International Conference of the International Building Performance Simulation Association. 2015. Hyderabad, India.

11. Reynders, G., 'Quantifying the impact of building design on the potential of structural storage for active demand response in residential buildings'. PhD thesis, (2015).

12. Candanedo, J., Saberi Derakhtenjani, A., D'Avignon, K. and Athienitis , A.K.(2018) 'A pathway for the derivation of control-oriented models for radiant floor heating applications'. esim 2018. 2018. Montreal, Canada.

13. Saberi Derakhtenjani, A., D'Avignon, K. and Athienitis , A.K.(2018) 'Development of a Predictive Control Methodology for a Hydronic De-icing System for Urban Infrastructure'. Intelligent Transport Systems (ITS) wrold congress 2018. 2018. Copenhagen, Denmark. 